\title{
Patrimonio: turismo y comunidad
}

\section{Sonia Tello Rozas}

El patrimonio y particularmente el Patrimonio Cultural se ha convertido en uno de los principales temas de discusión de la actualidad. La preocupación por conservar el pasado es notable durante los dos últimos siglos, la misma que pasa por el afán de algunos sectores de retener la memoria de sus herencias familiares (Urbano 1998), hasta el intento y dilema que actualmente afrontan muchas naciones del planeta de preservar el pasado sin dejar de construir el futuro, conciliar la cultura con el desarrollo (Mayor 1997).

Paralelamente se plantean problemas relacionados con el alto costo económico necesario para su mantenimiento, los recursos financieros que hagan posible su "aprovechamiento" por parte de la actuales generaciones y conservación para las futuras. Aparece así el turismo como una de las alternativas más atractivas para hacer factible la generación de ingresos que posibiliten mantener viva la riqueza patrimonial de los pueblos.

Ante el creciente desarrollo de la millonaria actividad turística mundial se presen$\tan$ nuevos enfoques que nos llevan a cuestionar la puesta en marcha de proyectos turísticos, de productos ofertados en el mercado internacional, en los cuales el patrimonio se torna en el insumo básico, un factor de producción.

Queremos mediante este artículo cuestionar el actual modelo de desarrollo turístico llevado a cabo en la mayoría de los países que conforman la rica y variada América Latina; rescatamos algunas experiencias que creemos válidas y analizamos otras que ciertamente deben ser mejoradas.

\section{De la conservación a la "rentabilización" del patrimonio}

La inquietud por la importancia de la conservación no es reciente, el deterioro y destrucción de restos arqueológicos e históricos (patrimonio monumental y artístico) motivaron a los gobiernos y a la comunidad internacional a buscar un consenso para establecer principios teóricos y metodológicos, conceptuales y jurídicos, de alcance internacional, para la intervención en favor de la protección, defensa y conservación del testimonio histórico - cultural. 
Poco a poco se hace evidente la necesidad de crear un movimiento internacional de protección de sitios, principalmente después de la decisión de construir la gran presa de Asuán, en Egipto, con lo que se inundaría el valle donde se encontraban los templos de Abú Simbel, tesoros de la civilización del antiguo Egipto, acontecimiento que suscitó una verdadera toma de conciencia internacional (Malraux 1997).

En 1959 la Organización de las Naciones Unidas para la Educación, la Ciencia y la Cultura (Unesco) decidió lanzar una campaña internacional a raíz del llamamiento de los gobiernos de Egipto y Sudán, tras la cual los templos de Abú Simbel y Filae fueron desmontados, trasladados y montados de nuevo.

La campaña costó cerca de 80 millones de dólares, la mitad de los cuales fueron donados por 50 países, demostrando así la importancia de una responsabilidad compartida entre las naciones para la preservación de los sitios culturales.

Con la ayuda del Consejo Internacional de Monumentos y Sitios (ICOMOS), representantes de la Unesco iniciaron la elaboración de un proyecto sobre la protección del patrimonio cultural. Así todas las partes interesadas se pusieron de acuerdo para aprobar en la Conferencia General de la Unesco de noviembre de 1972 la Convención sobre la Protección del Patrimonio Mundial Cultural y Natural.

En ella se señala que el patrimonio cultural está conformado por: Monumentos, obras arquitectónicas, de pintura, escultura o monumentales, elementos y estructuras de carácter arqueológico, lugares, obras del hombre y de la naturaleza; resumiendo éstas en dos grandes rubros : el monumental - cultural y el natural, el mismo que está constituido no sólo por la variedad de especies y procesos naturales, sino también por la capacidad del hombre para manejarlos y utilizarlos debidamente.

\footnotetext{
Posteriormente, en la declaración de México (06/08/92), se amplía el concepto,
}

afirmándose que el "patrimonio cultural de un pueblo comprende las obras de sus artistas, arquitectos, músicos, escritores y sabios, así como las creaciones anónimas, surgidas del arte popular y el conjunto de valores que dan un sentido a la vida. Es decir, obras materiales y no materiales que expresan la creatividad de un pueblo: la lengua, los ritos, las creencias, los lugares y monumentos históricos, la literatura, las obras de arte, los archivos y bibliotecas" (Bakula 1996: 40).

En los últimos veinte años la noción de patrimonio ha experimentado una "metamorfosis": definido inicialmente como el bien que se hereda de los antepasados, entendido después como el bien de la comunidad, del país y de la humanidad (Nora 1997).

Por medio de las convenciones internacionales y el consenso de muchos países, queda claro y se reconoce que forman también parte de la herencia que identifica a un pueblo, es decir de su patrimonio, aquellos rubros que tienen que luchar contra la percepción cotidiana del objeto, contra su ausencia física, tal es el caso del patrimonio oral tradiciones orales, literatura oral, historia oral, narraciones, cuentos, poesía, música, danza, como también las prácticas tradicionales y técnicas artesanales (Millones 1986). En suma: conocimientos y capacidades artísticas que se transmiten o circulan de boca en boca, sin pasar por el registro gráfico o documental.

El cambio de perspectiva y tratamiento dado al patrimonio, nos muestra también una nueva relación con el tiempo, la preocupación hoy no se centra sólo en la conservación de los grandes monumentos y vestigios del pasado, el patrimonio se enfoca como algo vivo (Micoud, 1997), que puede y debe ser utilizado en forma racional en beneficio de la población y de su desarrollo.

En este sentido y teniendo en cuenta que el "patrimonio vivo" no es eterno, que es un producto frágil, se procura hoy conciliar la protección y salvaguardia del patrimonio con la 
creación viviente, encontrar formas creativas y bien planificadas para que la riqueza patrimonial no quede estática, inmóvil y fuera de la vista de la gente para evitar su desgaste, sino que sea un medio posible para educar, integrar, entender y descubrir nuestras raíces.

Por estas razones, se afirma la necesidad de una efectiva "gestión del patrimonio", la que lamentablemente puede ser, y es muchas veces, orientada a desarrollar acciones cuya meta es la de obtener el máximo lucro y beneficio económico posible. La cultura deviene así en un producto más de la práctica capitalista, en un recurso económico que puede tornarse en atractiva fuente para la realización de rentables inversiones.

Queda claro que la conservación, protección y difusión del patrimonio, son actividades que requieren recursos económicos para poder llevarse a cabo y una de las formas más utilizadas hoy para "rentabilizar" el patrimonio y la cultura, es por medio del desarrollo de actividades turísticas.

Teniendo en cuenta la tendencia mundial, los problemas sociales a los que hoy se enfrentan principalmente los mal Ilamados "países del tercer mundo", el papel cada vez más reducido de los gobiernos en cuanto a la generación de ingresos y el protagonismo del mercado como asignador de recursos y regulador de las economías, somos conscientes de que son necesarias fuentes de financiamiento para mantener la riqueza patrimonial. El peligro reside en que este medio para conservar viva la memoria de un pueblo, se convierta en un objetivo y fin último.

\section{En busca de recursos económicos}

\section{El turismo y el patrimonio}

En las normas de Quito (1968), se contempla la valoración económica de los monumento; se afirma que las medidas conducentes a la preservación y adecuada utilización deben formar parte de los planes de desarrollo, se enfatiza también sobre el papel del turismo con relación a los monumentos. Se afirma que los valores culturales no se desnaturalizan al vincularse con los intereses turísticos, lejos de ello, la mayor atracción que conquistan los monumentos y la afluencia de admiradores foráneos, contribuye a afirmar la conciencia de su importancia. Se resalta también que Europa debe al turismo, directa o indirectamente, la salvaguardia de una gran parte de su patrimonio cultural condenado a destrucción (Bákula 1996).

Al respecto, en los años 60 se estimuló el desarrollo de la actividad turística hacia los llamados "países periféricos", dentro de ellos los países andinos. La principal justificación fue que el incremento del turismo receptivo aportaría divisas para aliviar los déficit en Balanza de Pagos, teniendo en cuenta la relevancia económica, en estos países, de la exportación de materias primas, y las consecuencias en cuanto a producción interna y necesidad de importar productos manufacturados.

Organismos internacionales como la Unesco y el Banco Mundial desatan así una intensa campaña dirigida a los países capitalistas periféricos para que abran sus fronteras al turismo internacional y para que otorguen a esta actividad un lugar prioritario dentro de sus programas de gobierno (otorgando incentivos fiscales y tributarios, garantías).

Siguiendo estos nuevos intereses se realizan inversiones para recuperar monumentos patrimoniales y se desarrolla el llamado "Turismo Patrimonial", que según la OMT, es la inmersión en la Historia Natural, herencia humana, artes, filosofía e instituciones de una región o país.

Una clara muestra de esta revaloración del patrimonio y la directa relación con las rentables actividades turísticas se pudo observar en la ciudad del Cuzco, Perú. En ella el interés por la conservación, y más precisamente por la restauración del patrimonio monumental, se da a partir de 1950 después del terremoto que afecta a un 
elevado número de iglesias, casonas coloniales y monumentos. Llega por este motivo una misión de la Unesco que da recomendaciones para la restauración y recuperación, principalmente, del Centro Histórico de la ciudad.

Posteriormente se crea el Instituto Nacional de Cultura, organismo encargado de aglutinar funciones hasta entonces realizadas por diferentes instituciones; de esta forma se buscan instrumentos que garanticen la conservación del patrimonio monumental, y se decide comenzar por la recuperación de un grupo de monumentos aislados y significativos, para plantear en el futuro la conservación integral del centro histórico.

A la par y dada la creciente importancia turística de la ciudad, se decide darle más atención e incluirla dentro de un plan general de desarrollo. Es a partir de 1960, siguiendo la tendencia mundial, que se da en el Perú mayor impulso a la actividad turística por medio de incentivos tributarios y crediticios para nuevas empresas prestadoras de servicios turísticos.

En Cuzco y las regiones aledañas, en los años anteriores a 1968 la actividad turística aún se presentaba como una actividad marginal dentro de la economía basada principalmente en la agricultura y la ganadería; no había una política coherente de explotación de los recursos turísticos, la infraestructura turística era deficiente, los monumentos se encontraban abandonados y los turistas que arribaban en ese entonces lo hacian en forma espontánea y $\sin$ ningún tipo de organización (Lovón 1982).

El Estado había intentado promover el desarrollo de la región mediante Juntas y Corporaciones de Fomento, intentos que fracasaron. Solo a partir de 1968, por el interés de la Unesco, del Banco Mundial y de algunos empresarios que deseaban invertir en la actividad, el gobierno realiza un inventario de los recursos de la región y "redescubre" el Cuzco como un espacio pobre en recursos naturales pero con ingentes atractivos monumentales e históricos que, explotados, significarían el desarrollo regional. En la década de los 70 el gobierno presenta y considera al turismo como única alternativa de desarrollo para las regiones de Cuzco, Puno y Madre de Dios, creando las condiciones jurídico - administrativas y económicas para hacer viable un programa de desarrollo frente al sector (Guillén 1982).

Mediante el Convenio Perú - Unesco se crea el Plan COPESCO, y de esa forma la actividad turística pasa a ser fuertemente impulsada por el Estado, que no sólo crea un marco legal favorable, sino también participa directamente en la ampliación y mejoramiento de los circuitos turísticos.

Con el Plan de Desarrollo 1971 - 1975 se marcan las pautas generales, se apunta la necesidad de impulsar programas de autoayuda basados en la Reforma Agraria $y$ complementados con el turismo y la artesanía. En el Plan de Desarrollo 1975-1978 se afirma que el desarrollo de la región se basa en la actividad turística y en su potencial minero - agropecuario, lineamientos que son reiterados en el Plan de Desarrollo 1979-1980.

Mediante la política sectorial que corresponde al turismo el gobierno pretendía hacer del Cuzco un mercado competitivo un polo de atracción turística, creando también interrelaciones entre la expansión de la actividad y las tradicionales actividades económicas.

Durante estos años el turismo junto con el comercio fueron las actividades de mayor rentabilidad, con tasas que en 1976 oscilaban entre $55 \%$ y $56 \%$. El turismo se mostraba como el sector más dinámico, aunque no el más importante, dentro de la estructura económica departamental.

Fue evidente la expansión del flujo y de la actividad turística, pero ésta no generó los esperados efectos colaterales en la economía, las variables fundamentales que según las previsiones básicas debían ser influenciadas, no fueron logradas; el efecto multiplicador no se tradujo en dinamizar la agricultura departamental y sí en el aumento de importaciones 
extrarregionales (Lovón 1982. Guillén 1982)¹.

Como Perú, muchos países latinoamericanos comienzan en los años 70 una "carrera competitiva" para atraer turistas. Los que poseen recursos excepcionales para desarrollary ofertar productos "sol y playa", combinados con monumentos históricos y monumentales, alcanzan gran éxito y desarrollan una infraestructura turística con servicios de primera calidad (véase el caso de los países del Caribe). Otros, como Costa Rica y Ecuador, logran llegar a un segmento del mercado que hace muy atractivo y lucrativamente beneficioso el "aprovechamiento" del patrimonio natural, por medio del llamado Ecoturismo.

En países con notables atracciones naturales, el turismo ha sido la principal justificación para la creación de áreas protegidas y parques nacionales. Por ejemplo el Parque Nacional de Galápagos en Ecuador, donde el turismo significa un ingreso directo de por lo menos US $\$ 700,000$ por año. Por lo general las poblaciones locales que viven en los alrededores de las áreas protegidas se caracterizan por sus bajos ingresos y pocas opciones económicas viables. Teóricamente el Ecoturismo puede representar para éstas una buena alternativa económica, con la ventaja adicional de que los habitantes pueden convertirse en eficientes guardianes de la zona, siempre que su bienestar dependa de la preservación de las cualidades naturales del medio ambiente; con frecuencia los habitantes locales poseen una práctica notable y el conocimiento ancestral de las características de su región (paisaje, flora, fauna), y con un entrenamiento adecuado pueden convertirse en muy buenos guías (Barzetti 1993).

También pueden participar directamente en actividades económicas derivadas de la operación de hoteles, restaurantes y otros servicios turísticos; se ha dado el caso de que las

\footnotetext{
${ }^{1}$ Al respecto V. Aguilar, L. Hinojosa y C. Milla (1992:.33) indican que, en la elaboración de las políticas específicas para el sector turismo presentadas en la década del 70, hubo ausencia de una concepción global de desarrollo para el país y la región, se separó la planificación turística de la planificación de otros sectores productivos.

${ }^{2}$ Las islas Galápagos, importantes desde el punto de vista cientifico por tornarse en un "laboratorio de la evolución " desde que fueron visitadas por
}

organizaciones comunales locales puedan actuar como concesionarias de los servicios, con un apropiado entrenamiento administrativo.

Un ejemplo claro es el proyecto piloto en el que las comunidades matziguenkas de Tayakome y Yomibato de la región de Madre de Dios - Perú, con el apoyo financiero de la Cooperación Alemana (GTZ) se convierten en las responsables de los servicios turísticos ofrecidos en la zona, a partir de la creación de una empresa cuyos beneficios futuros deberán ser destinados para la misma comunidad. Los pobladores de la zona saben que a través del desarrollo turístico pueden obtener ingresos económicos, pero están también conscientes de los riesgos que se corren. Motivo por el cual se toman las medidas necesarias para la prevención de la contaminación ambiental que el turismo pueda causar (Aguilar 1998).

El turismo en áreas protegidas no sólo trae con su desarrollo efectos positivos. Los costos pueden en algunos casos ser mayores a los posibles beneficios, ya que estas áreas no están inmunes de deterioro como resultado de una inadecuada utilización, de presiones de las poblaciones locales y del uso excesivo de parte de los turistas. Uno de los problemas que se enfrentan hoy en los parques y áreas naturales es cómo "arreglárselas" con el creciente número. de visitantes que buscan actividades recreativas en medios naturales.

Muchas de estas áreas visitadas por "ecoturistas" se apoyan en un frágil ecosistema que no puede soportar disturbios pesados. Es el caso del Parque Nacional de Galápagos, en el que la integridad ecológica se ve amenazada por la presión turística2 ${ }^{2}$ Se supone que la zona podía recibir un máximo de 12 mil turistas; en 1975 recibía 7,500 aproximadamente, número que

\footnotetext{
Charles Darwin, hicieron que el archipiélago fuera inscrito en 1978 en la Lista del Patrimonio Mundial. Casi veinte años después, en 1995, el Comité del Patrimonio Mundial planté su inclusión como patrimonio en peligro, por el deterioro ecológico causado principalmente por el turismo, la aceleración del asentamiento humano y la introducción de plantas y animales foráneos. El gobierno ecuatoriano procura hoy encontrar las vfas más eficaces para corregir la situación, por tal motivo se elabora un programa basado en la "ley especial de Galápagos", en la cual se regula e intenta corregir errores pasados. Nueva Ley para Galápagos - Revista Patrimonio Mundial. Unesco 1998.
} 
pasó a 32,500 en 1987. Este crecimiento sin control causa, sin duda, una severa degradación medio ambiental.

Por otro lado, muchos de los pobladores locales pueden percibir que las áreas protegidas fueron establecidas más para satisfacer los intereses extranjeros que los suyos. Extensas áreas muy importantes para la conservación de especies, pero que no atraen la atención de los turistas, son descuidadas por la administración; y si la ganancia es el objetivo principal de los agentes que "manejan" los parques, y sus expectativas no están siendo satisfechas por completo, ellos pueden procurar otros usos más lucrativos para el área: grandes hoteles, campos de golf y otras formas diseñadas para atraer más turistas, que fácilmente pueden disminuir el valor del parque natural y convertir el área en un lugar cuyo objetivo es el turismo de masa y no la conservación.

Los efectos positivos de esta forma de utilizar el patrimonio natural pueden ser considerables, pero los efectos negativos que acompañan inevitablemente el desarrollo del turismo tienen que ser tomados muy en cuenta para la planificación y efectivo manejo, no sólo de los recursos naturales sino también de los humanos, con el objetivo de maximizar la satisfacción del visitante y minimizar los impactos negativos que la actividad pueda traer.

Las cifras muestran que la importancia del turismo para las economías no es de ninguna manera irrelevante. Sólo en Perú, país que no está considerado ni siquiera entre los diez destinos americanos más importantes y que actualmente recibe más de 800 mil turistas por año (cifra nada representativa si es comparada con la que registran México, Cuba y otros) el turismo representa una de las principales fuentes generadoras de divisas, después de las tradicionales minería y pesca ${ }^{3}$.

\footnotetext{
${ }^{3}$ Según đatos macroeconómcos se observa en el Perú que los recursos mineros y pesqueros generaron 2,718 y 1,126 millones de dólares americanos. Los ingresos generados por el turismo fueron de 824 millones, convirtiéndose esta actividad en la tercera más importante en cuanto a generación de ingresos por exportaciones.
}

No cabe duda de los beneficios económicos que es posible obtener por medio de la oferta y venta de "productos" turísticos cuyo insumo básico y fundamental son los recursos patrimoniales. Sin embargo, las optimistas perspectivas futuras ponen en tela de juicio el racional aprovechamiento de nuestros recursos que, como lo señalábamos antes, son lamentablemente mortales y frágiles. Se hace imprescindible plantear planes de desarrollo turístico cuyo objetivo no sea sólo el de maximizar la cantidad de visitantes.

La falta de regulación, planificación y gestión adecuada pone en peligro también parte del patrimonio arqueológico de la región. Son conocidos los casos de Pisac, Ollantaytambo o Machu Picchu, importantes sitios arqueológicos de la cultura inca ubicados en la ciudad de Cuzco, en los cuales las empresas turísticas organizan visitas a muchos monumentos en pocos días, causando congestión, empeorando la prestación de servicios y deteriorando irreparablemente los monumentos.

Se llega al extremo de hacer optimistas proyecciones en cuanto a la llegada de visitantes, procurando atraer el interés de más turistas con "nuevos productos" y atractivas ofertas, sin contar con un estudio que indique los límites de carga física y psicológica de los monumentos y de los visitantes.

Por el gran interés que suscitan para el turismo los monumentos y restos del período incaico, se llevan a cabo fiestas que, se supone, evocan la memoria y costumbres ancestrales; es el caso de la fiesta del Inti Raymi donde, si bien es cierto, se generan ingresos interesantes, también se causa grandes estragos en Sacsayhuamán, recinto donde la fiesta es realizada. Como señala Blockley (1998), sería interesante replantear la gestión de eventos como el mencionado para que no se conviertan en simples productos comerciales.

No es extraño ver que algunos restos arqueológicos coloniales vienen desapareciendo por falta de un registro, gestión y promoción 
adecuados. Es el caso de los monumentos religiosos de Juli, provincia de Puno. Sólo una, la catedral del lugar, de las cuatro espléndidas iglesias que forman parte de su patrimonio monumental, está en condiciones aceptables de conservación, quizá por la función que desempeña al servicio de la comunidad católica. Otras dos reciben turistas esporádicamente, motivo por el cual conservan aún parte de sus obras de arte y se intenta conservar la estructura arquitectónica; la cuarta está, lamentablemente, "en ruinas".

Observamos así que en el mercado se presenta una nueva valoración turística del patrimonio que responde a las cambiantes tendencias de la demanda. Se intenta, en muchos de los destinos en los cuales el patrimonio demuestra su capacidad de atracción turística, ampliar la oferta y complementarla con otros atractivos para responder a la expectativa de cada vez mayor cantidad de visitantes, "tomando en cuenta que el turismo cultural es un negocio en el que muchos destinos compiten", razón por la cual se debe conocer muy bien qué es lo que el turista persigue, saber ofertarlo y obtener rentabilidad (Serra Cabado 1997).

Nos preguntamos entonces si la recuperación, valoración y conservación de nuestro patrimonio se realiza sólo porque éste es un recurso indispensable para la venta de productos turísticos y no porque constituya parte importante de la historia e identidad de un pueblo.

Creemos que todos los casos, que lamentablemente son muchos, en los cuales el patrimonio es depredado, maltratado y olvidado, presentan como elemento común el que, en los planes de desarrollo y manejo (en el caso de que éstos se hayan elaborado), no se involucra ni toma en cuenta el indispensable papel de la comunidad local.

¿Cómo ofertar al mundo un "producto" turístico basado en un recurso patrimonial, si el "heredero" del mismo no lo conoce, no lo aprecia, y no se siente involucrado en su recuperación, protección y salvaguardia?

\section{El patrimonio y la participación de la población}

Como señalamos anteriormente, el turismo es una forma interesante para conseguir recursos económicos que ayuden a mantener vivo el patrimonio, especialmente el monumental. Aunque sea considerado como un "mal necesario" en algunos casos, todos los países estamos adoptando este medio, mejor o peor planificado, para conseguir recursos financieros, teniendo en cuenta también el crecimiento en los flujos turísticos mundiales y la cada vez mayor importancia de esta actividad recreativa.

Es imprescindible, sin embargo, tener siempre presente que el principal beneficiario de la "utilización", rentable o no, del patrimonio debe ser el poblador.

Podemos encontrar casos interesantes en los cuales los planes de desarrollo turístico se hacen con el objetivo último de recuperar el patrimonio, para el disfrute, conocimiento y educación de los habitantes de una zona determinada. Haremos referencia al desarrollo del turismo en Cuba (Rigol, y Santamaría 1997), país en el que se dio impulso a la actividad partiendo de supuesto de que sus monumentos históricos, artísticos y naturales, constituían también recursos económicos.

Autoridades e instituciones responsables del patrimonio y del turismo en este país, dados los imperativos económicos, intentaron, a partir de los años 70 , identificar y unificar criterios para revalorizar sus riquezas patrimoniales teniendo en cuenta su potencial económico. Se dieron casos (como el de la Villa Trinidad) en los que, por iniciativa local, se restauraron monumentos arquitectónicos para convertirlos en museos y otras instalaciones culturales para la prestación de servicios a la comunidad, los mismos que atraían también a turistas que llegaban a la zona.

Durante la década de los años 80 , las autoridades responsables orientaron esfuerzos para recuperar el patrimonio de sus principales 
ciudades, y de esa forma una apreciable cantidad de edificios históricos recuperados en esa etapa se pusieron a disposición de la cultura y la recreación.

Dado el contexto internacional y las necesidades económicas de este país, el turismo se ha convertido en pieza fundamental para el desarrollo, adquiriendo la conexión entre cultura y turismo en los últimos años una notable importancia.

En casos específicos como el de la ciudad de La Habana, que cuenta con un impresionante centro histórico declarado como Patrimonio de la Humanidad, se intenta, por lo menos eso declaran y proclaman las autoridades responsables, establecer un efectivo mecanismo de retroalimentación económica para la recuperación y preservación patrimoniales, a partir de los ingresos generados por el turismo, que ayuden a llegar al fin último que es el de mejorar las condiciones de vida de la población de la zona, poniendo a su disposición no sólo "viviendas habitables" sino también nuevos espacios de educación y disfrute de la cultura local.

Si bien la realidad y el contexto político y económico del país al cual hacemos referencia es muy distinta al del resto de los países latinoamericanos, y podemos cuestionar algunos planteamientos de su política turística, como la clara diferenciación entre los servicios turísticos a los cuales la mayoría de los pobladores no pueden acceder (hoteles, restaurantes y otros), creemos que la experiencia de desarrollo turístico es interesante teniendo en cuenta que la población es el centro y objetivo de los proyectos realizados.

Se presentan también, en este país, experiencias que no están necesariamente relacionadas con el turismo, pero que se han convertido en un medio de involucrar al poblador en la gestión y cuidado del patrimonio. Una de ellas es la llevada a cabo en el Fanguito, barrio habanero ubicado a orillas del río Almendares, considerado insalubre y de alguna forma marginal, en el cual viven en condiciones precarias un grupo de personas procedentes de otras regiones del país. Se realiza en el barrio un proyecto de prevención social a partir de la incidencia en el arte (teatro, música, danza) y la literatura, brindando a la población, especialmente infantil, actividades por medio de las cuales ellos asumen la responsabilidad sobre los recursos naturales $y$, por ende, por los efectos negativos de la contaminación de su medio ambiente.

Otro ejemplo interesante de participación comunitaria es la que se presenta en Taquile, isla ubicada en el Lago Titicaca, región sur andina peruana, a $24 \mathrm{~km}$. de la ciudad de Puno, en la que la agricultura, la pesca y la confección textil son las tradicionales fuentes económicas desarrolladas por la población.

En los últimos años, el interés turístico por la zona se ha incrementado notablemente. Motivo por el cual los pobladores decidieron "monopolizar" los servicios turísticos, no permitiendo el ingreso de empresarios foráneos ${ }^{4}$. Son ellos los dueños de los servicios de alimentación, hospedaje y transporte, administrando los recursos y haciendo una distribución de los beneficios entre los miembros de la comunidad.

Si bien es cierto algunos visitantes e investigadores interesados en el particular desarrollo turístico de Taquile pueden cuestionar hoy los cambios sociales producidos a raíz de la llegada de visitantes en las últimas tres décadas, es importante reconocer que la población y los representantes de la misma, muestran su preocupación ante el abandono y sustitución de algunas actividades tradicionales por las turísticas así como el deterioro que se nota con la continua llegada de visitantes, y buscan posibles alternativas de solución, una de las cuales sería la restricción al turismo permitiendo entrada de visitantes a la isla determinados días de la semana.

Las experiencias y los ejemplos a los cuales podemos hacer referencia son muchos

\footnotetext{
${ }^{4}$ Actualmente se admite que lanchas de cooperativas de otras localidades transporten turistas hacia la isla, decisión tomada por la creciente demanda de visitantes y la insuficiente oferta del servicio de transporte.
} 
(Blockley 1998, Saito 1998), todos ellos nos muestran y no dejan lugar a dudas que para el éxito de un proyecto de recuperación, protección y salvaguardia del patrimonio, la población no debe sentirse ajena; más bien se deberá buscar las vías para que ésta se involucre y sienta un proyecto también suyo, convirtiéndola en uno de los ejes centrales y pilares básicos para la puesta en marcha del proyecto.

"Si el proyecto involucra a la comunidad local, particularmente a sus niños, bien podrían haber sentido una sensación de propiedad en vez de resentimiento ante una iniciativa que les ha sido impuesta. Estos problemas pueden ser superados involucrando a los pobladores locales en los procesos de reconstrucción e interpretación, y por lo tanto, elevando su nivel de conciencia y alentándolos a desempeñar un rol activo en la protección de la herencia arqueológica" (Blockley 1998: 27)

Así mismo, tenemos la certeza que uno de los primeros pasos para desarrollar mecanismos eficientes del conocimiento, defensa y conservación del Patrimonio es tomar conciencia de la importancia de la educación, una educación que permita no sólo acumular datos sino comprender el significado del patrimonio para nuestras sociedades, de aquella herencia que nos identifica, que nos da rasgos comunes, que nos diferencia de otros pueblos, una educación que forme parte de una política cultural coherente, con principios y prioridades que garanticen su continuidad.

Existen iniciativas interesantes que parten de los organismos internacionales encargados de promover la identificación y promoción del patrimonio relacionadas con proyectos educativos. Es el caso del proyecto de la Unesco orientado a estimular la participación de los jóvenes escolares en la conservación del patrimonio mundial. Se propone así tornarse un "Patrimonito", guardián juvenil del patrimonio, personaje jovial de historieta inspirado en el emblema del patrimonio mundial. Patrimonito, que simboliza el compromiso de los jóvenes con la salvaguardia del patrimonio, fue creado por un equipo de alumnos españoles en un taller sobre medios de información llevado a cabo en el primer foro Juvenil de la Unesco sobre Patrimonio Mundial (Beren - Noruega en junio de 1995).

El proyecto se inicia en 1994, época en la que la Unesco trabajaba con un amplio equipo de arquitectos, arqueólogos, historiadores, equipo que sintió que había llegado el momento de hacer participar a los jóvenes en la protección del patrimonio; se dio forma a un proyecto en ese sentido y fueron invitados 25 países a participar en él recogiendo el reto que se lanzaba: preparar planes, enseñar historia, geografía, ciencias, religión, idiomas, etc. desde el punto de vista del patrimonio mundial, organizar visitas a sitios y museos y aprovechar el potencial creativo de los alumnos.

Después del primer año, los profesores y alumnos de los países participantes se reunieron para confrontar experiencias y sacar conclusiones. Se formularon numerosas sugerencias sobre la elaboración de un proyecto de educación para el patrimonio mundial, que la Organización tuvo en cuenta para el programa. En los dos años siguientes, se realizaron esfuerzos para interesar a un número creciente de países en el proyecto, se realizaron encuentros regionales entre profesores y alumnos, durante los cuales se logró concebir planes de acción a nivel regional, se preparó material didáctico sobre patrimonio centrado en los temas de identidad, paz, medio ambiente y turismo (Kvisteroy 1998).

Claro está que es necesario que los países cuenten con un sistema y una política cultural y educativa que estimule el desarrollo y puesta en marcha proyectos "educativo - patrimoniales". El problema se presenta cuando no se cuenta con un marco institucional que sirva de respaldo a iniciativas, las cuales por ser particulares no alcanzan la difusión suficiente y quedan en meros esfuerzos aislados. 


\section{Los museos y la difusión del patrimonio}

Debemos destacar también el papel que pueden desempeñar los museos, considerados a veces y convertidos en algunos casos en "Arcas de Noé Culturales" con la única función de conservar objetos seleccionados.

La real función de los museo es mucho más amplia. Al ser agentes custodios de nuestras huellas, pueden y deben cumplir con el objetivo de recuperar y conservar objetos, estando al servicio de la investigación que facilite una interpretación y comprensión de la realidad de un pueblo, cumpliendo de esta forma su función de transmisión y difusión cultural (Dujovne. 1995).

La tarea de transmisión cultural no es fácil. Sin embargo, se ha demostrado con la experiencia de muchos museos que es posible, por medio de programas específicos para públicos distintos, crear vínculos con el entorno social.

Se presentan en algunos países de América Latina algunas experiencias interesantes, como el ecomuseo de São Cristovão en Río de Janeiro, por medio del cual se lleva a cabo a partir de 1980 un proyecto que tiene como objetivo reunir en torno a él a las entidades culturales (museos, escuela de samba, etc.) capaces de aglutinar y convocar a la población de este barrio ubicado al norte de la ciudad. Con la puesta en marcha del proyecto, el patrimonio, el territorio y la comunidad se convierten en elementos inseparables. La comunidad fue invitada a participar activamente sintiéndose protagonista activa, dinamizadora (Hernández 1998).

Otra iniciativa que vale la pena mencionar es la del "Museo Productivo", impulsada y llevada a cabo por el Museo de la Cultura Popular de Heredia, Costa Rica. El proyecto nace como respuesta al desinterés por la producción y desarrollo de oficios tradicionales de la zona y la necesidad de difusión y transmisión de técnicas ancestrales. El trabajo desarrollado no sólo incluye investigación y registro de los principales aspectos de la cultura popular, sino también actividades con miembros de la comunidad, activa participación de los niños y jóvenes a través de actividades especialmente diseñadas y programas conjuntos Museo - Escuela (De Carli 1997).

Lamentablemente en el ámbito de los países andinos, a pesar de la riqueza cultural y patrimonial y de las múltiples actividades que podría realizarse, los museos se han convertido en depósitos de conservación y fría exhibición de piezas, que en algunos casos no cuentan siquiera con datos confiables.

Es el caso del Museo Inca del Cuzco, un espacio recientemente restaurado que ofrece la posibilidad de realizar múltiples actividades recreativas y educativas en las que el poblador de la zona podría sentirse involucrado. Sorprende observar que objetos de la época colonial se encuentran erróneamente identificados, como si fueran del período inca. "Así mismo, las interpretaciones (presentadas en el museo) de la función que cumplían los diversos complejos incas y la planificación de su establecimiento, generaron especulaciones basadas en suposiciones histórico - artísticas, en lugar de presentar una información confiable y precisa de las evidencias arqueológicas" (Blockley 1998: 51)

En otros casos se restringe el ingreso del poblador local, como en el Museo de Arte Religioso de la misma ciudad, el mismo que alberga una importante y bella colección de la Escuela Cuzqueña, a la que el poblador no puede acceder si no cuenta con el "boleto turístico" (ticket equivalente a US $\$ 10$ que permite el ingreso a 15 monumentos de la ciudad y los alrededores). O el museo Dreyer de la ciudad de Puno, en el cual parte importante de su colección fue hurtada, exhibiéndose hoy una pobre muestra de material arqueológico en muy mal estado de conservación.

Por otro lado, no basta que el museo, como hacen muchos en el Perú, se contente con ofrecer cursos de extensión para públicos diversos, los cuales podrán ser fuentes financieras para sustentar su funcionamiento, pero de 
ninguna manera significan trabajo conjunto con la comunidad. Se hace imperativo que estas entidades lancen iniciativas y programas lo suficientemente atractivos, cambiar la concepción hasta hoy desarrollada y tomar en cuenta que más se aprende haciendo que viendo a través de una vitrina bien presentada.

\section{Conclusión}

El interés por temas relacionados con el patrimonio está creciendo, lo que en países como Perú es un elemento positivo, no sólo por la riqueza cultural sino también porque el patrimonio se ha visto gravemente deteriorado en los últimos años.

Sin embargo, no es suficiente el interés y dedicación de un grupo de intelectuales, estudiosos y "simpatizantes" del tema. Es imprescindible contar con un marco jurídico e institucional que permita hacer posible su conservación, valoración y racional utilización, involucrando al "socio" más importante: la población.

Por otro lado, las instituciones educativas no pueden contentarse con desarrollar cursos de especialización dirigidos a un grupo de profesionales interesados, que son sin duda imprescindibles dada la carencia de especialistas en temas relacionados con el patrimonio y su gestión; sin embargo se hace necesario también elaborar y poner en marcha proyectos que contemplen la participación de diversos sectores de la sociedad, para que los discursos sobre el tema de patrimonio no queden sólo en discursos.

Es indiscutible hoy el protagonismo del mercado como asignador de recursos, pero de ninguna manera podemos dejar que este mercado "decida" la mejor forma de utilización de los frágiles y mortales recursos patrimoniales. EI Estado, por medio de las autoridades responsables, deberá también asumir un papel activo y tener en cuenta que la gestión del patrimonio y de las actividades turísticas debe estar a cargo de especialistas y profesionales idóneos y capacitados.

Para finalizar, creo interesante recordar que en definitiva el patrimonio más importante, que debe ser conservado y respetado, es el humano, sin el cual ninguna otra forma de patrimonio tiene sentido.

\author{
Sonia Tello Rozas \\ Facultad de Turismo \\ Universidad San Martín de Porres \\ Lima, Perú \\ sotello01@ hotmail.com
}




\section{BIBLIOGRAFIA}

AGUILAR, Víctor; HINOJOSA, Leonith y otros. 1992. Turismo y desarrollo. Posibilidades de la Región Inca. Cámara Regional de Turismo - Centro de Estudios Regionales Andinos Bartolomé de Las Casas. Cuzco.

\section{BARZETTI, Valerie.}

1993. Parques y Progreso: Áreas Protegidas y Desarrollo Económico en América Latina y el Caribe. UICN - BID

BAKULA, Cecilia.

1996 El Patrimonio Cultural en sus textos. Banco Central de Reserva del Perú. Lima

BLOCKLEY, Marion.

1998 "Reconstrucciones arqueológicas y la comunidad". En: Revista Andina n. 31: Gestión Cultural en los Andes. Centro Bartolomé de Las Casas. Cuzco, julio.

DE CARLI, Georgina.

1997 The Productive Museum: Proposal for change" Instituto Latino Americano de Museología. Costa Rica.

DUJOVNE, Marta.

1995 Entre Musas y Musarañas. Una visita al Museo. Fondo de Cultura Económica. Buenos Aires.

GUILLEN, Jesús.

1982. El desarrollo del Cusco: Balance de unas ilusiones 1950-1982. Centro Bartolomé de Las Casas. Cuzco.

HEALVY, Kevin; ZORN, Elaine.

1994 "Turismo controlado por campesinos en el lago Titicaca". En: Expresión Cultural y Desarrollo de Base. Quito
HERNANDEZ, Francisca.

1998 El museo como espacio de comunicación. Ed. Trea. España.

LOVÓN, Gerardo.

1982 Mito y realidad del turismo en el Cusco. Centro Bartolomé de Las Casas. Cuzco

MAYOR, Federico.

1997. "El patrimonio, memoria del porvenir". En: En: El correo de la Unesco. Nro. 22:

El Patrimonio Mundial, balance y perspectivas. Unesco. Setiembre

SAITO, Hidetoshi; INABA, Nobuko.

1997. "Aldeas salvadas por sus habitantes". En: El correo de la Unesco. Nro. 22: El Patrimonio Mundial, balance y perspectivas. Unesco. Setiembre.

SERRA CABADO, Joan.

1997 Metodología para el diseño de productos turísticos culturales: el caso de Cartagena. IV Congreso AECIT: Turismo, ciudad y patrimonio cultural en el sur de Europa e Iberoamérica. España, noviembre.

KVISTEROY, Ingunn.

1997 "Los jóvenes guardianes del patrimonio". En: El correo de la Unesco. Nro. 22: EI Patrimonio Mundial, balance y perspectivas. Unesco. Setiembre

MICOUD, André

1997 "Museé et patrimoine: deux types de rapports aux choses et au temps". En: Hermes Nro. 20. Paris

NORA, Pierre.

1997 "Una noción en devenir". En: El correo de la Unesco. n. 22: El Patrimonio Mundial, balance y perspectivas. Unesco. Setiembre.

OSSIO, Juan; MILLONES, Luis y otros.

1986 Patrimonio Cultural del Perú. Balance y Perspectivas. Formiciencias. Lima. 
RIGOL, Isabel; SANTAMARÍA, Jorge.

1997 "El patrimonio Cultural y el Turismo en Cuba". En: Turismo Cultural en América Latina y el Caribe. Unesco. La Habana.

URBANO, Henrique.

1998 "Gestión Cultural en los Andes". En: Revista Andina n. 31: Gestión Cultural en los Andes. Centro Bartolomé de Las Casas. Cuzco, julio.

UNESCO.

1997 "¿Qué es patrimonio mundial?". En: El correo de la Unesco. Nro. 22: El Patrimonio Mundial, balance y perspectivas. Unesco. Setiembre

1998 "Nueva Ley para las Islas Galápagos". En: Revista del Patrimonio Mundial n. 8. Unesco. Madrid.

ZELADA AGUILAR, Edson.

1998. "Ecoturismo en la comunidad matzigenka". En: El Comercio de Lima. p. E, 10 de mayo. 